\title{
Study of serum zinc and copper level in children with malarial infection in Civil Hospital, Ahmedabad
}

\author{
Vikas K Vaghela $^{1, *}$, Bhavika K Vaghela ${ }^{2}$, Jaivik K Vaghela ${ }^{3}$ \\ ${ }^{1,3}$ Resident, ${ }^{2}$ Associate Professor, Dept. of Biochemistry, ${ }^{1,2} \mathrm{~B}$ J Medical College, Ahmedabad, ${ }^{3} \mathrm{C}$ U Shah Medical \\ College, Surendranagar, Gujarat, India
}

*Corresponding Author:

Email: drvikaskvaghela@gmail.com

\begin{abstract}
Introduction: Malaria is a major protozoal disease in developing countries responsible for 2-3 million deaths per year. Zinc $(\mathrm{Zn})$ and copper $(\mathrm{Cu})$ are involved in numerous aspects of cellular metabolism. They are required for the catalytic function of several enzymes, play essential roles in immune function and act as antioxidants. So this study will give us a proper view whether there is a need for a more study on zinc supplementation in these patients.

Material and Method: Fifty children with Malaria are included in the study as cases and equal number of age and sex matched healthy children formed the control group. Study is conducted during the period of August 2014 to October 2016.

Result: In the present study mean Zinc level was significantly lower in cases as compared to controls (P value is 0.0426 which is less than 0.05$)$ and mean Copper levels was significantly higher in cases as compared to controls $(\mathrm{p}<0.001)$.

Conclusion: Children having malaria has low serum zinc levels as compare to healthy controls is due to excessive production of free radicals. They having malaria has high copper levels as compare to healthy controls is due to competitive absorption of zinc and copper. So the zinc supplementation is necessary for the immunity against plasmodial infection and to decrease the toxicity of copper in our body.
\end{abstract}

Keywords: Children, Copper, Malaria, Zinc.

Received: $27^{\text {th }}$ July, 2017

\section{Introduction}

Malaria is a major disease in developing countries responsible for 2-3 million deaths per year. Malaria is a protozoan disease which is transmitted by bites female Anopheles mosquitoes. It is mainly caused by different species of plasmodium parasite. Out of these four species of intracellular protozoa of the Plasmodium has been found to be responsible for malaria in humans which include P. falciparum, P. vivax, P. ovale, P. malariae and P. knowlesi. $P$. falciparum and P. Vivax cause the most severe forms of the disease. ${ }^{1-2}$

Zinc $(\mathrm{Zn})$ and copper $(\mathrm{Cu})$ plays a vital role in cellular metabolism. They are required for the catalytic function of several enzymes, play essential roles in immune function and act as antioxidants. $\mathrm{Zn}$ also plays a role in wound healing, protein synthesis, DNA synthesis and cell division. Maintaining a proper balance of copper and zinc is important as excess $\mathrm{Zn}$ impairs $\mathrm{Cu}$ absorption. The ratio of $\mathrm{Cu}$ to $\mathrm{Zn}$ is clinically much more important than the concentration of either of them. Copper is essential also for maintaining the strength of the skin, blood vessels, epithelial and connective tissues. It takes part in production of hemoglobin, myelin and melanin. ${ }^{3-9}$

Apart from these well-known functions, $\mathrm{Zn}$ and $\mathrm{Cu}$ also play a critical role in host-pathogen interactions. $\mathrm{Zn}$ is required for each step of cell cycle in microorganisms. $\mathrm{Cu}$ is an essential component of cuprozinc superoxide dismutase; an enzyme in the erythrocytes essential for host defense as well as parasite growth.

Due to zinc's crucial role in immune system function, and recent evidence that zinc supplementation appears to reduce malaria morbidity; we have determined serum zinc and copper levels of children with or without malaria in civil hospital Ahmedabad. This is essential because its result will guide us whether there is a necessary of further study on zinc supplementation in these patients.

\section{Materials and Methods}

The present study is designed as Crosssectional study, having children of age group 0 12 years selected from civil hospital and B.J Medical College, Ahmedabad, Gujarat. Study is done during the August 2014 to October 2016. 
All patients were primarily checked by clinical examination.

Sample size: Fifty children with malaria are included in the study as cases and equal number of age and sex matched healthy children formed the control group.

Inclusion criteria: Children with malaria whose smear positive for p.vivax/p.falciparum are included as cases and those smear negative and apparently healthy are included as control. Blood samples that passed acceptable criteria by the laboratory Standard Operational Procedure were included in the study.

Exclusion criteria: Children with: a) Chronic infection like tuberculosis, HIV; b) Malabsorption syndrome, protein losing nephropathy; c) Endocrine disorders; d) Typhoid fever, dengue fever and meningitis

Sample Collection: For Serum Serun Zinc and Copper, $5.0 \mathrm{ml}$ of blood collected with clot activator plain vaccute and samples are transported to the lab at $2-8^{\circ} \mathrm{C}$ immediately. Ensured the complete clot formation has taken place before to centrifugation in red/yellow vaccute. Some specimens, especially those from patients receiving anticoagulant or thrombolytic therapy, may show increased clotting time. Serum is removed from the clot within 2 hours of drawing the sample. If testing was delayed for more than 24 hours, serum specimens are stored at $2-8^{\circ} \mathrm{C}$ and analyzed next day as per criteria (Ueland PM 1993). ${ }^{9}$

Sample Analysis: All samples are immediately analysed subjected to assays for Serum Zinc and Serum Copper after thawing at $37^{\circ} \mathrm{C}$. The measurement of Serum Zinc and Serum Copper levels are analysed on an Erba XL 640 Fully Automated Analyzer by kit of crest biosystems, a division of coral clinical systems.

Serum zinc estimation: Zinc which is in an alkaline medium reacts with Nitro-PAPS .So that a purple coloured complex forms. Colour Intensity of this purple coloured complex is directly proportional to the amount of Serum Zinc present in the given sample.

Zinc + Nitro-PAPS $\longrightarrow$ Purple Coloured

Complex

Serum Copper estimation: Copper,which is released from ceruloplasmin in an acidic medium, reacts with Di-Br-PAESA so that a coloured complex forms. Colour Intensity of this complex is directly proportional to the amount of Copper present in the sample.

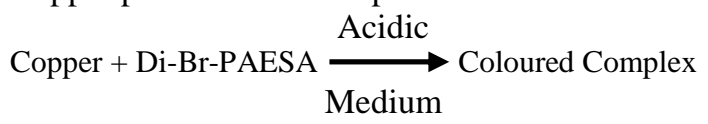

Data Analysis: Data was analyzed by unpaired $\mathrm{t}$ - test using graphpad prism version 3.03 statistical software which evaluated the differences of various parameters in both group cases and control on the basis of $p$ value.

Interpretation was done by $\mathrm{p}$-value

$\{\mathrm{P}<0.05$ - Significant, $\mathrm{P}<0.001$ - Highly significant, $\mathrm{P} \geq 0.05$ - Not significant $\}$

\section{Result}

Table 1: Age distribution of cases and control:

\begin{tabular}{|l|c|c|}
\hline $\begin{array}{c}\text { Age groups } \\
\text { (Years) }\end{array}$ & Cases $(\mathbf{N}=\mathbf{5 0})$ & Controls $(\mathbf{N}=\mathbf{5 0})$ \\
\hline $\begin{array}{l}\text { Mean age } \\
\text { (years) } \pm \text { SD }\end{array}$ & $6.16 \pm 3.31$ & $6.46 \pm 3.27$ \\
\hline P value is 0.6495 & \\
\hline
\end{tabular}

Table 2: Sex distribution of cases and control

\begin{tabular}{|l|c|c|c|c|}
\hline \multirow{2}{*}{ Gender } & \multicolumn{2}{|c|}{ Cases ( N=50) } & \multicolumn{2}{c|}{ Control (N=50) } \\
\cline { 2 - 5 } & No. & \% & No. & \% \\
\hline Male & 26 & 53 & 27 & 54 \\
\hline Female & 24 & 48 & 23 & 46 \\
\hline Total & 50 & 100 & 50 & 100 \\
\hline
\end{tabular}

Majority of the children (53\% in cases, 54 $\%$ in controls) were males. Results showed that there was no statistically significant differrence in the gender distribution among cases and controls.

In the present study 50 children of age group of $0-12$ years with malaria positive are enrolled as cases, equal number number of healthy children formed the control wing. Both cases and control group were age and sex matched. Higher morbidity and mortality in this age group required greater precaution from malaria.

Table 3

\begin{tabular}{|l|c|c|}
\hline & Cases & $\begin{array}{c}\text { Percentage } \\
(\boldsymbol{\%})\end{array}$ \\
\hline P.vivax & 36 & 72 \\
\hline p. falciparam & 14 & 28 \\
\hline Total & 50 & 100 \\
\hline
\end{tabular}

In the present study, $72 \%$ cases were found for by P. vivax and $28 \% \quad \mathrm{P}$. falciparum.

Comparison of S. Zinc levels between case \& control group: 
Table 4: Comparison of Serum Zinc

\begin{tabular}{|l|c|c|}
\hline \multicolumn{1}{|c|}{ Group } & S. Zinc (case) & S. Zinc (control) \\
\hline Mean & 86 & 93 \\
\hline Standard Deviation (SD) & 20.03 & 13.38 \\
\hline Sample Size & 50 & 50 \\
\hline Std. error of Mean (SEM) & 2.8327 & 1.8922 \\
\hline Minimum & 44 & 56 \\
\hline Maximum & 144 & 121 \\
\hline Significance & $\mathrm{t}=2.0549, \mathrm{df}=98, \mathrm{p}=0.0426$ \\
\hline
\end{tabular}

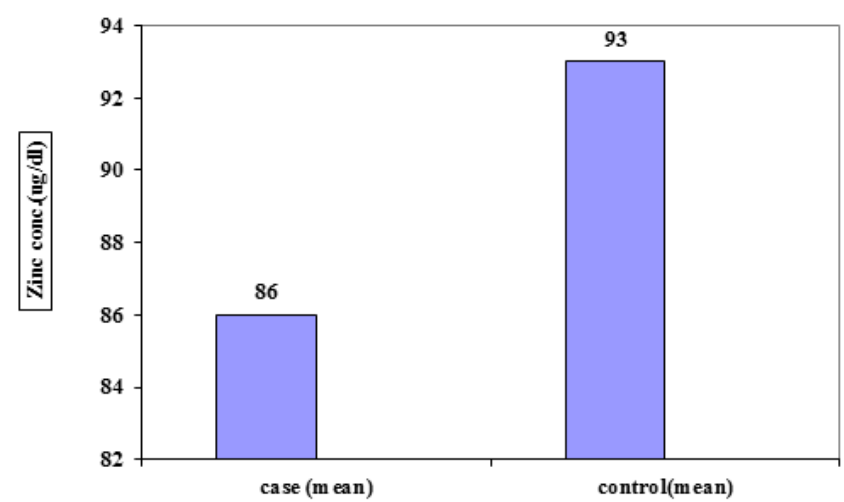

Fig. 1: Comparison of Mean Serum Zinc level in cases and controls

As shown above there is significant difference in serum zinc levels in cases and controls ( $\mathrm{p}$ value is 0.0426)

Comparison of S. Copper levels between case \& control group:

Table 5: Comparison of Serum Copper

\begin{tabular}{|l|c|c|}
\hline \multicolumn{1}{|c|}{ Group } & S. Copper (case) & S. Copper (control) \\
\hline Mean & 186 & 86 \\
\hline Standard Deviation (SD) & 38.95 & 23.38 \\
\hline Sample Size & 50 & 50 \\
\hline Std. error of Mean & 5.5084 & 3.3064 \\
\hline Minimum & 82 & 24 \\
\hline Maximum & 279 & 126 \\
\hline Significance & $\mathrm{t}=15.5653, \mathrm{df}=98, \mathrm{p}<0.0001$ \\
\hline
\end{tabular}

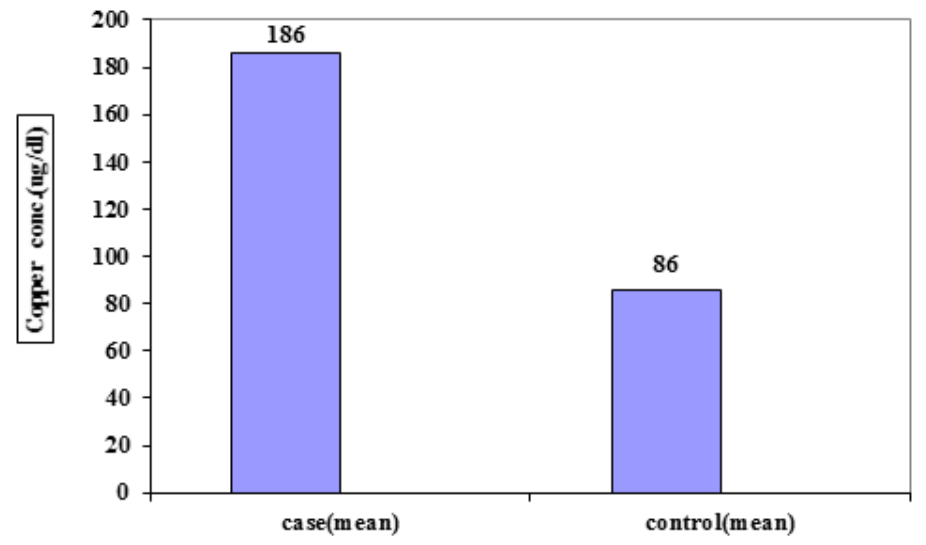

Fig. 2: Comparison of Mean Serum Copper levels in cases and controls 
As shown above there is significant difference in serum copper levels in cases and controls ( $p$ value is less than 0.0001)

\section{Discussion}

Present study is undertaken to know the status of serum Zinc, Copper levels in children with malaria.

In the present study, $72 \%$ cases were found for by P. vivax and $28 \%$ P. falciparum. However, other studies have showed an incidence of $51.6 \%$ for P. vivax, $47.1 \%$ mixed and only $1.1 \%$ of $\mathrm{P}$. falciparum. A higher frequency of $P$. vivax $(52 \%)$ has also been reported by other studies but this is lower as compared to our result. ${ }^{11-13}$ As our study is conducted in civil hospital Ahmedabad so most of the patients came from the area around Ahmedabad where prevalence of $P$. vivax is more than $P$. falciparum.

\section{Serum ZINC}

In the present study mean Zinc level was significantly lower in cases as compared to controls ( $\mathrm{P}$ value is 0.0426 which is less than $0.05)$. Results of the present study correlate with studies conducted by Chimah et al, Melaine G. M'boh et al and Kulkarni. ${ }^{14-15}$

Study conducted by Chimah found that mean zinc levels decreased significantly $(\mathrm{p}=0.0002)$ with progressive increase in parasitemia. The critical low level of serum zinc in children with may be because of increased consumption/utilization of zinc which result from the increased production of tumour necrosis factor and other free radicals produced in severe malaria. ${ }^{14}$

Kulkarni et al had reported that there is increased production of these free radicals, in severe/complicated malaria. So that lower zinc level is mediated by exaggerated production of free radicals and may reflect a normal protective mechanism.

Study conducted by Melaine G. M'boh also found that mean zinc levels was significantly lower in infected children as compared to controls $(\mathrm{p}<0.0001)$ which is also match with our study. ${ }^{15}$

Result of our study is well supported by the above mentioned studies. So the role of zinc is crucial for the immunity of the person so it can defend the foreign organism. Zinc supplementation should be advised.

\section{Serum COPPER}

In the present study mean Copper levels was significantly higher in cases as compared to controls $(\mathrm{p}<0.001)$. Results of the present study correlate with studies conducted by S Baloch et al, Seyrek A et al and Alfarazdeg A. Saad et al. ${ }^{16-}$

According to study conducted by S Baloch et al, $\mathrm{Zn}$ and $\mathrm{Cu}$ are always compete with each other for their absorption in GI tract, a diet, which is excessive in one of these trace minerals, may show deficiency of the other. According to this we can assume elevated $\mathrm{Cu}$ levels in Malaria within low level of Zinc. ${ }^{16}$

Seyrek A et al also found that copper levels were significantly higher in patients with Plasmodium vivax malaria than in the controls which also match with our study. ${ }^{17}$

Result of our study is well supported by the above mentioned studies. Copper absorption is increased from GI Tract. So it may produce toxicity so the serum level of copper is should also be monitored.

\section{Conclusion}

Children having malaria has low serum zinc levels as compare to healthy controls which could be due to excessive production of free radicals. Those having malaria has high copper levels as compare to healthy controls which could be due to competitive absorption of zinc and copper. So the zinc supplementation is necessary for the immunity against plasmodial infection and to decrease the toxicity of copper in our body. As this study having small sample size further study is required for the proper justification of zinc supplementation during the plasmodial infection.

These data will also help the National Malaria Control Programme (NVBDCP) to target control strategies aimed at reducing malaria morbidity.

\section{References}

1. Akaninwor JO, Essien EB, Chikezie PC, et al. Haematologic and biochemical indices of Plasmodium falciparum infected inhabitants of Owerri, Imo State, Nigeria. Glob J Med Res Dis. 2013;13(4):20-8.

2. Kamble P, Bhagwat V, Trivedi DJ, et al. Comparative study of free radical activity in Plasmodium falciparum and Plasmodium vivax malaria patients. Int J Pharm Bio Sci. 2011;2(4):99-102.

3. Classe HG, Grose U, Low D,et al. Zinc deficiency: Symptoms, causes, diagnosis and therapy. Med Moratschr Pharm. 2011;34:87-95 
4. Formhe GJ. Zinc toxixity. Am J of Clin Nutr. 1990;51:225.

5. Jeremy E. Kaslow. Copper/zinc imbalance; 2011. Available: www.mbc.ca.gov Accessed 29th September 2011. (Cited: 25th September 2011).

6. Mccartey TJ, Zeelle JJ, Karse DJ. The antimicrobial action of zinc and antiozidant combinations. Clinical Pharmacology and Therapeutics. 1992;17:5.

7. Prasad As. Zinc: An overview. Nutrition. 1995;11:93-9.

8. Sarstead HH. Understanding zinc: Reactions, observqations and interpretations. J Lab Clin Med. 1994;124:322-7.

9. Shmmer K, Thompson RP. Zinc in the newborn. Acta Paediatr Scard Suppl.1985;319:158-63.

10. Ueland PM, Refsum H, Stabler SP et al. Total homocysteine in plasma or serum: methods and clinical applications. Clin Chem 1993;39:176479.

11. Beg MA, Sani N, Mehraj V, et al. Comparative features and outcomes of malaria at a tertiary care hospital in Karachi, Pakistan. Int J Infect Dis 2008. Jan;12(1):374210.1016/j.ijid.2007.04.006.

12. Faseela TS, Ronald AR, Anita KB, et al. Diagnostic Value of Platelet Count in Malaria. Journal of Clinical and Diagnostic Research 2011;5:464-6.

13. Malik AM, Zaffar N, Ali Nadir, et al. Hematological Findings And Endemicity of Malaria In Gadap Region. Journal of the college of Physians and Surgeons 2010; 20:112-6.

14. Kulkarni AG, Suryakar AN, Sardeshmukh A, et al. Studies on biochemical changes with special references to oxidant and antioxidants in malaria patients.Indian Journal of Clinical Biochemistry, 2003:136.

15. Melaine G. M'boh, Felix H Yapi, Hugues T Ahiboh, et al. The effect of falciparum malaria infection on the quantity of trace elements (iron, copper, zinc) in the blood in children of Côte d'Ivoir, Agric. Biol. J. N. Am., 2010,1(4):565-70.

16. Saira Baloch, Bikha Ram Devrajani, Marya Baloch, et al. Determination of Trace Metals concentration in patients with falciparum Malaria by Atomic Absorption Spectroscopy. Nature and Science 2013;11(4).

17. Seyrek A, Kocyigit A, Erel O. Essential trace elements selenium, zinc, copper and iron concentrations and their related acute-phase proteins in patients with vivax malaria. Biol Trace Elem Res 2005;106:107-15.

18. Zinc, Copper and C-reactive Protein in Children with Severe Plasmodium falciparum Malaria in an Area of Unstable Malaria Transmission in Eastern Sudan Journal of Tropical Pediatrics , October 2012. 